\title{
The Role of Human Herpesvirus 8 Molecular Characterization in the Management of HIV Infected Patients Diagnosed with Malignancies Associated with Its Infection
}

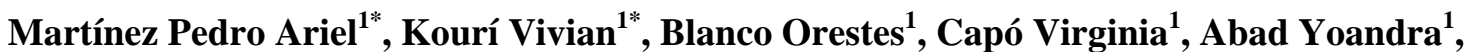 \\ Alemán Yoan ${ }^{1}$, Verdasquera Denis ${ }^{1}$, Jiménez Narciso ${ }^{1}$, Caballero Iraida ${ }^{2}$, Fleites Gilberto ${ }^{1}$, \\ Ugarte Yaumara $^{1}$, Calderón Odalys ${ }^{1}$, Álvarez Alina ${ }^{1}$, Ulrich Hengge ${ }^{3}$ \\ ${ }^{1}$ Institute of Tropical Medicine "Pedro Kourí” (IPK), Autopista Novia del Mediodía, Habana, Cuba; “"Hermanos Ameijeiras” Hospi- \\ tal, Havana, Cuba; ${ }^{3}$ Haut Zentrum (Skin Center), Dusseldorf, Germany. \\ Email: arielmr@ipk.sld.cu, arimaroz@infomed.sld.cu
}

Received April 16 ${ }^{\text {th }}, 2013$; revised May $16^{\text {th }}, 2013$; accepted June $16^{\text {th }}, 2013$

Copyright (C) 2013 Martínez Pedro Ariel et al. This is an open access article distributed under the Creative Commons Attribution License, which permits unrestricted use, distribution, and reproduction in any medium, provided the original work is properly cited.

\begin{abstract}
Despite the progress has been reached with Human herpesvirus 8 (HHV-8) research, there are gaps in the knowledge of viral induced oncogenesis. The aim of the present study was to identify possible associations between HHV-8 subtypes, HHV-8 loads and clinical manifestations of HIV infected patients diagnosed with different malignancies associated with HHV-8 infection. Forty six HIV-1 infected individuals diagnosed with different HHV-8 associated diseases were studied [37 epidemic Kaposi's sarcoma (KS), 3 pleural effusion lymphoma (PEL); 5 peripheral lymphadenopathies (PL); 1 Hodgkin's lymphoma (HL); 1 non Hodgkin's lymphoma (NHL)]. HHV-8 loads were determined by quantitative real time PCR (qRT-PCR) whilst HHV-8 subtypes were determined by open-reading frame (ORF)-K1 gen genotyping. HHV-8 subtypes B, A, C, A5 and E were exhibited by $31.8 \%, 23.4 \%, 19.1 \%, 17 \%$ and $8.5 \%$ of the studied patients, respectively. The median HHV-8 viral load did not differ between subtypes $(\mathrm{p}>0.05)$ but HHV-8 viral loads were significantly higher in PEL than in epidemic KS lesion or lymph nodes $(\mathrm{p}=0.04)$. Subtype B was detected in $60 \%$ of patients with B cell lymphoma (NHL, PEL and HL) whereas subtype E was only detected in patients with epidemic KS diagnosis. Our data suggest that HHV-8 DNA quantification instead of subtype identification could be used as a surrogate marker for monitoring its infection, not only in epidemic KS patients but also in HIV infected individuals with lymphoproliferative disorders.
\end{abstract}

Keywords: Human Herpesvirus 8 or Kaposi's Sarcoma-Associated Herpesvirus; Real Time PCR; Subtypes; Lymphoproliferative Disorders; Cuban; HIV/AIDS

\section{Introduction}

HHV-8 also referred as Kaposi's Sarcoma-Associated Herpesvirus is the first known human Rhadinovirus which belongs to the Gammaherpesvirinae subfamily, Herpesviridae family. It is implicated as the causative agent of all clinical forms of Kaposi's Sarcoma (classical, epidemic, endemic and iatrogenic), PEL and multicentric Castleman's disease (MCD) [1] but its role in other lymphoproliferative disorders has not been clearly established. Although the HHV-8 genome is highly conserved along most of the unique coding region (approx. $145 \mathrm{kbp}$ ), sev-

${ }^{*}$ These authors have equally contributed. eral genomic regions display remarkable sequence variability making them useful markers of strain diversity and potential epidemiologic patterns of HHV-8 spread. Five major subtypes are recognized by K1 genotyping: A, $\mathrm{B}, \mathrm{C}, \mathrm{D}$ and $\mathrm{E}$. The $\mathrm{K} 1$ protein is highly variable in its cysteine-rich $\mathrm{N}$-terminal ectodomain and its amino acid sequence has been shown to vary by up to $40 \%$, with changes concentrated in two hypervariable regions (VR1 and VR2) [2].

The influence of particular subtypes on disease progression remains largely unknown. Therefore, it is importent to identify biological markers related with HHV- 
8 -associated diseases outcome. Some authors have alerted that the risk of KS remains substantially increased in HIV infected subjects and further decreases have not been observed [3]; being KS recently diagnosed in patients with controlled HIV infection and CD4 counts over 200 $\mathrm{T}$ cells [4]. Epidemic KS incidence has not been significantly reduced in Cuba although locally produced antiretroviral drugs started being introduced as a form of treatment since 2001. Previous studies have shown that, with the exception of subtype D, the majority of HHV-8 subtypes were circulating among Cuban HIV population $[5,6]$. However, a change in HHV-8 subtype distribution was recently identified with an increase in subtype B detection [7]. Thus, we decided to identify how viral factors (K1 subtype and viral load) may impact on the oncogenesis induced by HHV-8 among HIV infected individuals diagnosed with different malignancies.

\section{Materials and Methods}

\subsection{Patients and Samples}

The study was approved by local and national ethics committees. All participants provided their written informed consent to participate in the study. Forty six HIV-1 infected individual diagnosed with HHV-8 associated diseases between 2005 and 2011 inclusive were included and different samples were collected (Table 1). One patient contributed with two samples since KS in the lymph node was diagnosed six month after the initial diagnosis of PEL in the pericardium. The diagnosis of vasoproliferative lesion of the lymph node and the AIDS-related complex lymphadenitis were based on the histopathological diagnosis as described elsewhere [8]. Clinical, immunological and epidemiological data from each patient were obtained throughout a retrospective review of individual's clinical records and are depicted in Table 2.

\subsection{Sampling and DNA Extraction}

DNA was extracted from frozen tissues samples by QIAamp ${ }^{\circledR}$ DNA Mini Kit (QIAGEN, Germany), according to the protocol for DNA purification from tissues described by the manufacturer. In contrast, $200 \mu \mathrm{L}$ of the effusion fluid from PEL patients and the sample of saliva obtained from the patient diagnosed with Hodgkin lymphoma were used to purify DNA using the same kit but following the protocol for blood or body fluids. Genomic DNA (gDNA) concentration was determined by spectrophotometer (GeneQuant II, Pharmacia Biotech, USA) and adjusted to $100 \mathrm{ng}(10 \mu \mathrm{L})$.

\section{3. qRT-PCR for HHV-8 DNA Quantification}

An "in-house" Taqman methodology based qRT-PCR was used for HHV-8 quantification in clinical samples. The protocol conditions, primers and probe were described by Watzinger et al. [9] with minor modifications adapted for the LightCycler 1.5 [10]. The HHV-8 loads were expressed as copies/100 ng of DNA. Human $\beta$ globin was amplified by Real Time PCR using primers, probes and the protocol previously described elsewhere [11].

\subsection{DNA Sequencing of HHV-8 ORF K1}

A fragment of ORF-K1 gen was amplified by nested PCR from the assayed samples following the protocol published elsewhere [2]. PCR products from nested PCR were purified using MiniEluteTM Purification Kit (QIAGEN, Germany) following the manufacturer's protocol and their final concentration were evaluated throughout horizontal electrophoresis in $2 \%$ agarose gel stained with ethidium bromide $(0.5 \mu \mathrm{g} / \mathrm{mL})$ and visualized through a UV transilluminator.

The Kit Dye labeled dideoxy Terminator Cycle Sequencing from Beckman Coulter (USA) was used for nucleotide sequence analysis, following the manufacturer recommendations. One hundred fentomoles of PCR products were added to a mixture containing $1 \mu \mathrm{l}(5 \mathrm{pmol})$ of either forward or reverse primer (LGH2090 and LGH2508), $8 \mu 1$ of sequence reaction mixture (DTCS Quick Star Master Mix) and water up to a final volume of $20 \mu \mathrm{l}$. The sequencing reaction was conducted by 50 cycles of two minutes at $96^{\circ} \mathrm{C}$ for 20 seconds, $50^{\circ} \mathrm{C}$ for 20 seconds and finally $60^{\circ} \mathrm{C}$ for 4 minutes. The obtained fragments were purified following the manufacturer instructions. Finally, the purified products underwent electrophoresis on a Beckman Coulter CEQ8800 sequencer.

\subsection{Sequence Analysis}

Initial evaluation of each sequence was performed using the nucleotide search engine BLAST at NCBI (USA), to confirm that the amplified product was K1. Then, nucleotide sequences were manually edited with both forward and reverse primers using MEGA version 4 [12]. To determine the K1 subtype of each subject's strain(s), nucleotide sequences were aligned by Muscle in Jalview version 2.4 [13] along with the following reference strains obtained from Genetic sequence database (Gen-Bank) at the National Center for Biotechnology Information (NCBI) [AF133038 (A1); AF130305 (A2); U86667 (A3); AF133039 (A4); AF178823 (A5); AF133040 (B1); AF130259 (B2); AF133041 (C1); AF133042 (C3); AF133043 (D1) AF133044 (D2); AF220292 (E)].

Maximum likelihood (ML) trees were estimated using PAUP 4.0 beta under the best-fit substitution model calculated by Modeltest 3.7 [14] using the Akaike information criterion. New HHV-8 nucleotide sequences and the 

Infected Patients Diagnosed with Malignancies Associated with Its Infection

Table 1. HHV-8 subtypes identified by ORF-K1 genotyping from HIV-1 infected individuals in which HHV-8 associated diseases were diagnosed between 2005 and 2011 inclusive.

\begin{tabular}{|c|c|c|c|c|c|c|}
\hline Specimen ID & Age & Gender & $\begin{array}{l}\text { KSHV } \\
\text { subtype }\end{array}$ & Diagnosis material & Histopathological diagnosis & $\begin{array}{c}\text { Accession } \\
\text { number }\end{array}$ \\
\hline Cub-B06-576 & 22 & Female & A5 & Tissue & Kaposi's sarcoma & FJ986113 \\
\hline Cub-81/07 & 31 & Male & A5 & Tissue & Kaposi's sarcoma & FJ986114 \\
\hline Cub-209/06 & 35 & Male & A & Tissue & Kaposi's sarcoma & FJ986115 \\
\hline Cub-551/06 & 46 & Male & A5 & Tissue & Kaposi's sarcoma & FJ986116 \\
\hline Cub-2033/05 & 29 & Male & A5 & Tissue & Kaposi's sarcoma & FJ986117 \\
\hline Cub-758/06 & 36 & Male & A5 & Tissue & Kaposi's sarcoma & FJ986118 \\
\hline Cub-310/07 & 44 & Male & A & Tissue & Kaposi's sarcoma & FJ986119 \\
\hline Cub-B06-603 & 22 & Male & A & Tissue & Kaposi's sarcoma & FJ986120 \\
\hline Cub-473/07 & 35 & Male & A & Tissue & Kaposi's sarcoma & FJ986121 \\
\hline Cub-1064/06 & 30 & Male & A & Tissue & Kaposi's sarcoma & FJ986122 \\
\hline Cub-2032/05 & 45 & Male & B & Tissue & Kaposi's sarcoma & FJ986123 \\
\hline Cub-553/06 & 41 & Male & B & Tissue & Kaposi's sarcoma & FJ986124 \\
\hline Cub-737/06 & 46 & Male & B & Tissue & Kaposi's sarcoma & FJ986126 \\
\hline Cub-557/06 & 41 & Male & B & Tissue & Kaposi's sarcoma & FJ986128 \\
\hline Cub-1373/07 & 42 & Male & B & Tissue & Kaposi's sarcoma & FJ986129 \\
\hline Cub-626/06 & 39 & Male & B & Tissue & Kaposi's sarcoma & FJ986131 \\
\hline Cub-1109/06 & 37 & Male & B & Tissue & Kaposi's sarcoma & FJ986132 \\
\hline Cub-1835/06 & 36 & Male & B & Tissue & Kaposi's sarcoma & FJ986133 \\
\hline Cub-427/07 & 41 & Male & B & PEL pleural & Kaposi's sarcoma & FJ986134 \\
\hline Cub-9/07 & 41 & Male & $\mathrm{E}$ & Tissue & Kaposi's sarcoma & FJ986135 \\
\hline Cub-1105/06 & 50 & Male & E & Tissue & Kaposi's sarcoma & FJ986136 \\
\hline Cub-127/07 & 29 & Male & E & Tissue & Kaposi's sarcoma & FJ986137 \\
\hline Cub-286/07 & 43 & Male & $\mathrm{C}$ & Tissue & Kaposi's sarcoma & FJ986138 \\
\hline Cub-296/09 a & 25 & Male & $\mathrm{C}$ & PEL pericardium & PEL & FJ986139 \\
\hline Cub-134/06 & 29 & Male & $\mathrm{C}$ & Tissue & Kaposi's sarcoma & FJ986140 \\
\hline Cub-234/06 & 57 & Male & $\mathrm{C}$ & Tissue & Kaposi's sarcoma & FJ986141 \\
\hline Cub-1106/06 & 36 & Male & A & Tissue & Kaposi's sarcoma & FJ986142 \\
\hline Cub-556I/06 & 30 & Male & A & Tissue & Kaposi's sarcoma & FJ986143 \\
\hline Cub-375/07 & 35 & Male & $\mathrm{C}$ & Tissue & Kaposi's sarcoma & FJ986144 \\
\hline $1 \mathrm{~T} / 2009$ & 32 & Male & A5 & Lymph node & AIDS-related complex lymphadenitis & GU475457 \\
\hline $17 \mathrm{~T} / 2009$ & 34 & Male & B & Lymph node & KS in the lymph node & GU475458 \\
\hline $32 \mathrm{~T} / 2009$ & 25 & Male & A & Lymph node & Vasoproliferative lesion of the lymph node & GU475459 \\
\hline $50 \mathrm{~T} / 2009^{\mathrm{a}}$ & 25 & Male & $\mathrm{C}$ & Lymph node & $\mathrm{KS}$ in the lymph node & GU475460 \\
\hline Cub-58LN/2009 & 43 & Male & B & Lymph node & non Hodgkin's lymphoma & JF979530 \\
\hline
\end{tabular}


Continued

\begin{tabular}{rrrrccc}
\hline Cub-59S/2009 & 19 & Male & B & Saliva & Hodgkin's lymphoma & JF979531 \\
Cub-62LN/2009 & 37 & Male & A5 & Lymph node & AIDS-related complex lymphadenitis & JF979532 \\
Cub-147T/2011 & 55 & Male & B & Tissue & Kaposi's sarcoma & JF979533 \\
Cub-151T/2010 & 29 & Male & B & Tissue & Kaposi's sarcoma & JF979534 \\
Cub-213T/2010 & 43 & Male & A5 & Tissue & Kaposi's sarcoma & JF979535 \\
Cub-275T/2011 & 46 & Male & A & PEL peritoneal & PEL & JF979536 \\
Cub-516T/2009 & 33 & Male & E & Tissue & Kaposi's sarcoma & JF979537 \\
Cub-762T/10 & 47 & Female & B & Tissue & Kaposi's sarcoma & JF979538 \\
Cub-763T/2010 & 38 & Male & A & Tissue & Kaposi's sarcoma & JF979539 \\
Cub-1426T/2009 & 28 & Male & A & Tissue & Kaposi's sarcoma & JF979540 \\
Cub-1629T/2009 & 34 & Male & A & Tissue & Kaposi's sarcoma & JF979541 \\
Cub-1501T/2009 & 44 & Male & C & Tissue & Kaposi's sarcoma & JF979542 \\
Cub-1680T/2010 & 58 & Male & C & Tissue & Kaposi's sarcoma & JF979543 \\
\hline
\end{tabular}

a. nucleotide sequences belongs to the same patient.

Table 2. Descriptive data of HIV-1 infected individuals diagnosed with HHV-8 associated diseases.

\begin{tabular}{|c|c|c|}
\hline Variables & $\begin{array}{l}\text { Studied population } \\
\qquad \mathrm{N}=46\end{array}$ & \\
\hline Median age & $\begin{array}{c}37.4 \text { years } \\
\text { (Range } 22-58)\end{array}$ & \\
\hline \multirow[t]{2}{*}{ Gender } & Female & $2(4.3 \%)$ \\
\hline & Male & $44(95.7 \%)$ \\
\hline \multirow[t]{3}{*}{ Race } & White & $32(69.6 \%)$ \\
\hline & Mulatto & $10(21.7 \%)$ \\
\hline & Black & $4(8.7 \%)$ \\
\hline \multirow[t]{2}{*}{ Sexual behavior } & Heterosexual & $5(10.9 \%)$ \\
\hline & $\begin{array}{l}\text { Men who have sex } \\
\text { with men (MSM) }\end{array}$ & $41(89.1 \%)$ \\
\hline $\begin{array}{l}\text { Median HIV viral } \\
\text { load* (copies/mL) }^{*} \text { (mis }\end{array}$ & $\begin{array}{c}90,634 \\
\text { (Range } \leq 50-580,000)\end{array}$ & \\
\hline $\begin{array}{l}\text { Median CD4+ T cell } \\
\left.\text { count (cells/mm } / \mathrm{mm}^{3}\right)\end{array}$ & $241($ Range $=8-884)$ & \\
\hline \multirow[t]{3}{*}{ CD4+ T cell count } & $<200$ & $21(45.7 \%)$ \\
\hline & $200-499$ & $25(54.3 \%)$ \\
\hline & $>500$ & - \\
\hline
\end{tabular}

*Data not available for six patients.

derived aminoacid (aa) sequences were deposited in GenBank using the National Center for Biotechnology Information (Bethesda, MD).

Throughout Sequin Application version 11.0. The
GenBank accession numbers for 46 new sequences obtained in this manuscript are: FJ986113 to FJ986144, GU475457 to GU475460, JF979530, JF979532 to JF979543.

\subsection{Statistical Methods}

IBM SPSS Statistics package version 19 and Epidat version 3.1 were used to process all the data. ANOVA test was performed in order to compare the values of HHV-8 loads among identified subtypes, histopathological diagnosis and different compartments in which the tumor arise. Contingency tables were constructed and Chisquare test or Fisher's exact test were used for comparing data. Odds ratios (OR) and their $95 \%$ confidence intervals $(\mathrm{CI})$ were used to assess the association between variables. HHV-8 sequences obtained from the same individual were included separately for statistical analysis since they were amplified at different times from different diseases. The value of HHV-8 loads in saliva from the patient diagnosed with HL was not included in the analysis.

\section{Results}

The phylogenetic characterization allowed the identification of different HHV-8 subtypes among the studied individuals (Figure 1). HHV-8 subtypes B, A, C, A5 and E were exhibited by $31.8 \%, 23.4 \%, 19.1 \%, 17 \%$ and $8.5 \%$ of the studied patients, respectively. Overall, no statistical associations were discovered between HHV-8 subtypes and the following variables: CD4+ T cell counts, HIV-1 loads, sex and age ( $p>0.05)$. 


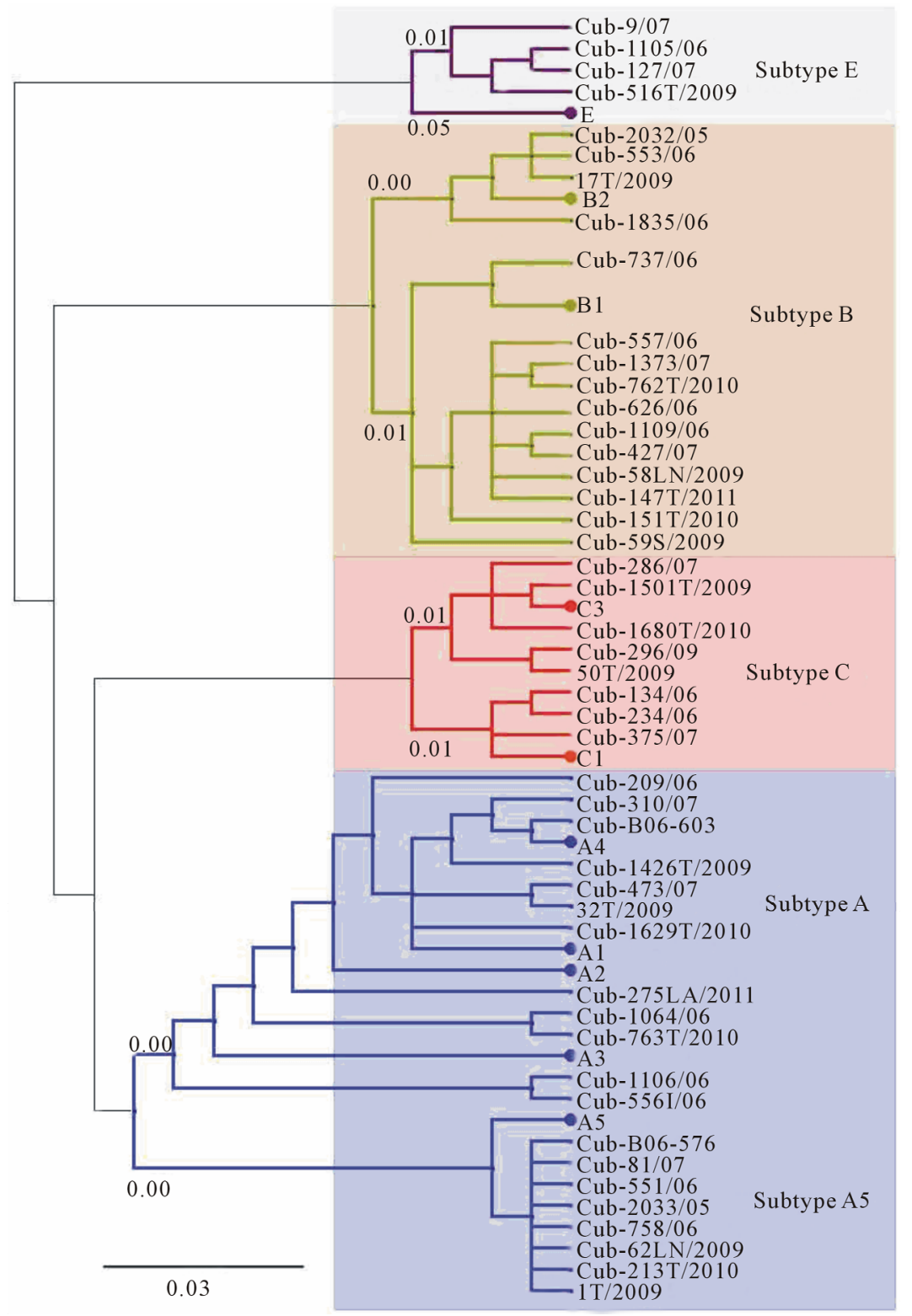

Figure 1. Unrooted maximum likelihood tree generated by PAUP 4.0 beta under the best-fit substitution model calculated by Modeltest 3.7 using the Akaike information criterion with a fragment of the K1 gene of $\mathrm{HHV}-8$. Branch lengths are drawn to scale, with the bar indicating 0.03 -nt replacement per site. Numbers on each node indicate the $p$ value by which the cluster is supported. References strains were labeled with circles $(\bullet)$.

There were no significant differences in subtypes frequencies among HHV-8 associated diseases $(p>0.05)$ (Table 3). No statistical differences were found among K1 subtypes when the median elapsed time between HIV diagnosis and HHV-8 associated diseases appearance were compared $(p=0.444)$. Nevertheless, individuals infected with subtype E and A5 seem to progress slower to HHV-8 associated diseases than individuals infected by subtypes A, B or C. No differences were detected between the median copy number of each identified HHV-8 subtypes irrespective the histhopathological diagnosis
( $p>0.05$ ) (Figure 2). However, the median HHV-8 viral load was significantly higher in PEL than in epidemic KS lesion or lymph nodes $(\mathrm{p}=0.04)$ (Figure 3$)$.

\subsection{Epidemic KS}

Patients diagnosed with epidemic KS showed a wide range of subtypes although strains belonged to subtype $\mathrm{E}$ were only identified in the tissue of these patients (Table 3). Nodular stage of epidemic KS were identified in 12/37 (patients $32.4 \%$ ) whilst $8 / 37(21.6 \%)$ and $2 / 37(5.4 \%)$ were considered to be in macular and patch stage; 


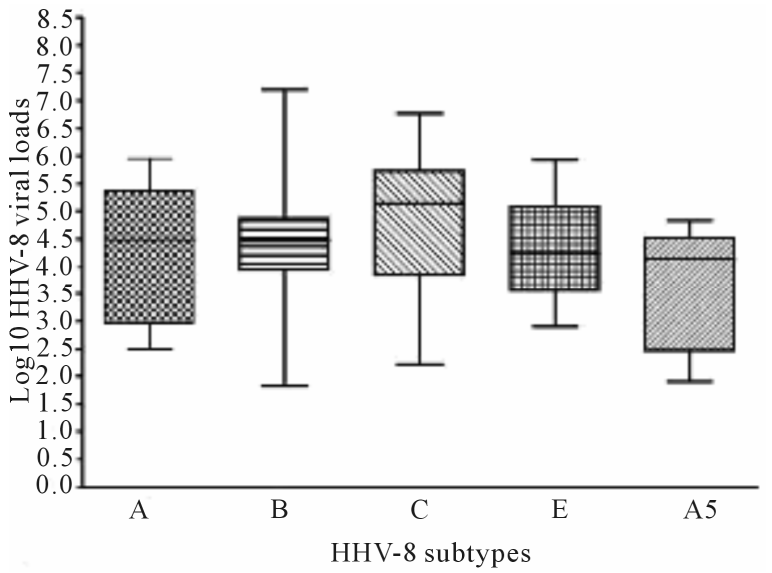

Figure 2. Logarithmic HHV-8 viral loads between subtypes identified from HIV-1 infected individuals diagnosed with different HHV-8-associated diseases (2005-2011).

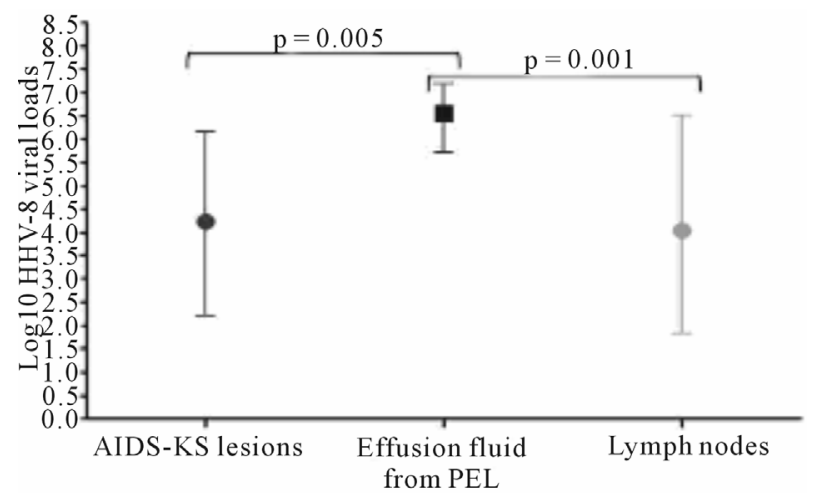

Figure 3. Logarithmic HHV-8 viral loads between different anatomic sites in which samples were collected from Cuban HIV-1 infected individuals diagnosed with different HHV8-associated diseases (2005-2011).

respectively. No associations were identified between the histological stages, HHV-8-subtypes and their DNA copy number in the affected tissue ( $\mathrm{p}>0.05)$. However, 15 of 37 obtained biopsies $(40.5 \%)$ were not classified by histopathological analysis.

\subsection{B Cell Lymphoma}

Subtype B was detected in 3/5 studied patients diagnosed with B cell lymphoma (NHL, PEL and HL) but PEL patients exhibited different HHV-8 subtypes (Table 3). EBV DNA was also detected in all the studied effusion fluid by qRT-PCR (data not shown). Subtype B (58LN/ 2009) was detected in an HIV infected patient diagnosed with NHL of immunoblastic subtype which had no prior history of KS but he was markedly immunosuppressed $\left(\mathrm{CD} 4+\mathrm{T}\right.$ cell count 112 cells $\left./ \mathrm{mm}^{3}\right)$. In contrast, $\mathrm{Cub}$ 59S/09 (subtype B) was isolated from a mixed cellular subtype of a Hodgkin lymphoma patient's saliva. Although HHV-8 DNA was not amplified in the lymph node 22,980 copies/100 ng of DNA were found in saliva by qRT-PCR Higher EBV DNA copies number was also quantified in the saliva and lymph node collected both from NHL and Hodgkin lymphoma patients (data not shown).

\subsection{Peripheral Lymphadenopathies}

Different subtypes were exhibited by patients diagnosed with peripheral lymphadenopathies (Table 3). No history of KS lesions on the skin or mucous surface neither on chest X-rays, abdominal scan and upper digestive tract endoscopy revealed signs of visceral KS. Patients diagnosed with AIDS-related complex lymphadenitis exhibited subtype A5 and they showed an enlargement of the lymph node as the only clinical sign (1T/2009: cervical area; Cub-62LN/2009: axillary area). HIV-1 infection was diagnosed few months the beginning of lymph node swollen. They had a CD4+ T cells counts over 200 cells whilst their HIV-1 loads were 27,000 and 30 copies $/ \mathrm{mL}$; respectively. The detected copy numbers of HHV-8 DNA in the lymph node were 79 and 495 copies/100 ng of gDNA, respectively. Subtypes A5 were significantly associated with the diagnosis of AIDS-related complex lymphadenitis $(\mathrm{p}=0.0271)$.

KS was diagnosed in two lymph nodes fragments of the studied HIV-1 infected individuals. The first one exhibited subtype C (50T/2009) which was identified in the lymph node of patient who complained of a swollen of the cervical area with no other symptoms at the time by which KS diagnosis was made. He had a previous history of a PEL at the pericardium (Cub-296/09). Both aa sequences grouped in the same branch of the tree $(\mathrm{p}=$ 0.032) (Figure 1) however visual comparison of the alignment showed specific changes (50T/2009: G191A, L197S, L213I, P254H). His CD4+ T cell count was 142 cells $/ \mathrm{mm}^{3}$ and the copy number of HHV-8 DNA in the lymph node was 215,100 copies/100 ng of gDNA. The second individual in whom KS was diagnosed resulted to be infected by subtype B (17T/2009) and complained a localized enlargement of lymph nodes in the inguinal area, accompanied by fever. His CD4+ T cell count was $300 \mathrm{cells} / \mathrm{mm}^{3}$ and the HIV-1 viral load was 14,000 copies $/ \mathrm{mL}$. The determined value of HHV-8 DNA in the lymph node was 3,300,000 copies/100 ng of gDNA.

The vasoproliferative lesion of the lymph node was diagnosed in an AIDS rapid progressor admitted due to a three month history of fever, weight loss, cervical mass, fatigue and dyspnea. On the physical examination a remarkable paleness of the mucous surface and skin were noted, accompanied by spleen enlargement. Laboratory examination showed severe anemia $(4.5 \mathrm{~g} / \mathrm{L})$ and increased erythrocyte sedimentation rate $(130 \mathrm{~mm})$. The patient was severe immune depressed $(\mathrm{CD} 4+\mathrm{T}$ cell 
Infected Patients Diagnosed with Malignancies Associated with Its Infection

Table 3. Distribution of HHV-8 subtypes according the histopathological diagnosis of the studied samples (2005-2011).

\begin{tabular}{|c|c|c|c|c|c|}
\hline & \multicolumn{5}{|c|}{ HHV-8 subtypes } \\
\hline & A & $\mathbf{B}$ & C & $\mathbf{E}$ & A5 \\
\hline Epidemic KS & $919.2 \%$ & $1123.4 \%$ & $715 \%$ & $48.5 \%$ & $612.8 \%$ \\
\hline \multirow[t]{3}{*}{ B cell lymphoma } & PEL & $12.1 \%$ & $12.1 \%$ & $12.1 \%$ & - \\
\hline & HL & - & $12.1 \%$ & & \\
\hline & NHL & - & $12.1 \%$ & - & - \\
\hline KS in the lymph node & - & $12.1 \%$ & $12.1 \%$ & - & - \\
\hline AIDS-related complex lymphadenitis & - & - & - & - & $24.2 \%$ \\
\hline $\begin{array}{l}\text { Vasoproliferative lesion of the } \\
\text { lymph node }\end{array}$ & $12.1 \%$ & - & - & & \\
\hline Total & $1123.4 \%$ & $1531.8 \%$ & $919.1 \%$ & $48.5 \%$ & $817 \%$ \\
\hline
\end{tabular}

PEL: pleural effusion lymphoma; HL: Hodgkin's lymphoma; NHL: non Hodgkin's lymphoma.

count: 163 cells $/ \mathrm{mm}^{3}$ ) and the HIV-1 viral load was 160,000 copies/mL. Hepatomegaly and splenomegaly were found on the abdominal scan. Subtype A (32T/2009) was identified by nucleotide sequence analysis with a total amount of 900,000 copies/100 ng of gDNA in the lymph node.

\section{Discussion}

Although some authors have pointed that viral factors are not likely to play an important role in HHV-8 oncogenesis [15], the available evidence is not conclusive and they need to be explored thoroughly. So far, differences in the replication rates by HHV-8 subtypes have not been reported. The possible impact of HHV-8 subtypes and their viral load in disease pathogenesis have been difficult to evaluate before. Perhaps, the low incidence of HHV-8 associated diseases in populations at risk and also the restricted geographical subtype's distribution have confined its assessment. Present findings suggest that HHV8 oncogenicity is not related to specific subtype demonstrating that there are not differences between their replicative capacities.

In contrast, it was known that HHV-8 viral loads in affected tissue should be considered as an important marker for monitoring its infection. In agreement with others [16-18], the obtained data highlight that HHV-8 load varied among anatomic sites and it would be related with the histhopathological diagnosis being higher in PEL. Those findings support the usefulness of qRT-PCR in HHV-8 diagnosis and underline the existence of not well defined viral characteristic that allows HHV-8 maintenance, replication and also its capacity to transform target cells into a malignant one among different neoplasms [19]. Unfortunately, those mechanisms are not well understood yet.
Interestingly, like the previous report from Cassar and colleagues [20], Cuban E subtypes were detected in epidemic KS lesions whereas it seems to be rarely associated with $\mathrm{KS}$ in Brazilian Amerindians [21]. Thus, it would indicate that the Cuban subtype $\mathrm{E}$ has evolved to a more invasive variant which can transform endothelial cells or maybe the lower frequency of Amerindian's alleles among Cuban population [22] has predisposed the appearance of $\mathrm{KS}$, not only the epidemic but also the classical variant [23].

The development of a variety of lymphoproliferative disorders due to $\mathrm{B}$ cells infection by HHV-8 have been previously reported by others [24]. Nevertheless, it was not previously demonstrated in Cuba. Present data have expanded the spectrum of HHV-8 associated diseases among HIV population; maybe, the role of HHV-8 in malignant lymphoproliferation was underestimated before. It reveals the significance of HHV-8 diagnosis for the management of those malignancies arising in HIV population which may be predominantly caused by subtype B.

Now, there is a controversy around the participation of HHV-8 in NHL. In this sense, some authors have also agreed that HHV-8 DNA detection in the lymph node would be considered not only as opportunistic infection but also as an agent involved in malignant lymphoproliferation [25]. Furthermore, rare HHV-8 positive solid lymphomas have been described as extra-cavitary PELs forms [26] and Engels and colleagues have previously reported a similar case of NHL from Ugandan pediatric patient [27]. On the other hand, it is possible that HHV-8 may be shed in saliva from HIV infected patient diagnosed with Hodgkin lymphoma, its role in this malignancy has not been established before. Accordingly, it has to be pointed that the number of studied patients with lymphoma diagnosis is limited. Therefore, the participation of HHV-8 in lymphoproliferative disorders will need to be 
established in the future.

The studied PEL cases were the first to be diagnosed since the beginning of Cuban AIDS epidemic in 1986. At present, it is revealed that PEL can be caused by different HHV-8 subtypes. In addition, the K1 amino acid changes that were identified in the strain isolated from the same individual are in agreement with the results obtained by Lacoste and colleagues [28]. However, others have obtained contrasting results [29] suggesting that K1 variation did not occur over the lifetime of a single infected host. Even though ORF-K1 mutation rates were identified to be similar to genes in other human pathogens [e.g. gen env from HIV-1 [2], there are neither evidences of error-prone replication mechanism that would permit HHV-8 positive selection not specialized mechanisms to rapidly generate a high level of diversity [30]. The causes of this extreme variability are not well understood but host immune pressure seems to be one of the possible explanations. However, the effects of Taq polymerase error prone during PCR amplification would not be definitely excluded.

The clinical characteristic of HHV-8 primary infection has not been well defined. The first report was done by Oksenhendler and colleagues in an HIV subject [31] and it has been latter described in renal and bone marrow transplant recipients [32,33] as in children from Egypt and Africa [34,35]. Conversely, its occurrence has been difficult to prove since previous serological status is difficult to establish. HHV-8 DNA detection at lymph node fragments obtained from Cuban patients diagnosed with AIDS-related complex lymphadenopathy and vasoproliferative lesion of the lymph node would be indicative of its primary infection, since neither signs nor symptoms of KS or other HHV-8 associated diseases were identified. Unfortunately, the seroconversion to HHV-8 was impossible to identify since no serum samples collected before the onset of symptoms were available. Thus, it would be impossible to arrive to this diagnosis in the Cuban studied patients. However, a closer follow up was recommended to clinicians since those individuals were recognized at risk of developing malignancies associated with this Gammaherpesvirus. The association between subtype A5 with AIDS-related complex lymphadenitis as a form of HHV-8 primary infection will need to be elucidated in the future since a small number of patients were included.

Overall, our findings suggest that although different HHV-8 subtypes circulate among Cuban HIV-1 population, it is not necessary to determine the infecting subtype for their clinical management. In contrast, HHV-8 viral load could be used as a surrogate marker for monitoring its infection, not only in epidemic KS patients but also in those diagnosed with different lymphoproliferative disorders. Moreover, it was elucidated that the spectrum of
HHV-8 associated diseases has expanded among Cuban HIV population irrespective the K1 subtypes. Others host factors will need to be explored in the future if HHV-8 transmission would need to be limited among Cuban HIV population.

\section{Acknowledgements}

The corresponding author is grateful for the training received at the 16th International Bioinformatics Workshop on Virus Evolution and Molecular Epidemiology in Rockville, USA, September 2010 (http://www.rega.kuleuven.be/cev/workshop/); and for the travel grant supported by Vlaamse Interuniversitaire Raad (VLIR) (ZEIN2008PR358). Likewise, he would like to thank the professors working on the Computational Molecular Evolution course that he attended 10 - 21 April 2011 run by Wellcome Trust Advanced Courses. We are also indebted to Dr. Mariana Varela from the Department of Veterinary Medicine, University of Cambridge, Cambridge, UK for the support in data analysis and also to Dr. Maria Nascimento, PhD, from the London School of Hygiene and Tropical Medicine for her suggestions in the manuscript writing.

\section{REFERENCES}

[1] D. Ganem, "Kaposi's Sarcoma-Associated Herpesvirus," In: D. M. Knipe and P. M. Howley, Eds., Fields Virology, 5th Edition, Lippincott Williams \& Wilkins, 2007, p. 2847-2888.

[2] J. C. Zong, D. M. Ciufo, D. J. Alcendor, X. Wan, J. Nicholas, P. J. Browning, et al., "High-Level Variability in the ORF-K1 Membrane Protein Gene at the Left End of the Kaposi's Sarcoma-Associated Herpesvirus Genome Defines Four Major Virus Subtypes and Multiple Variants or Clades in Different Human Populations," Journal of Virology, Vol. 73, No. 5, 1999, pp. 4156-4170.

[3] S. Franceschi, L. D. Maso, M. Rickenbach, J. Polesel, B. Hirschel, M. Cavassini, et al., "Kaposi Sarcoma Incidence in the Swiss HIV Cohort Study before and after Highly Active Antiretroviral Therapy," British Journal of Cancer, Vol. 99, No. 5, 2008, pp. 800-804. doi: $10.1038 /$ sj.bjc. 6604520

[4] T. Maurer, M. Ponte and K. Leslie, "HIV-Associated Kaposi's Sarcoma with a High CD4 Count and a Low Viral Load," New England Journal of Medicine, Vol. 357, No. 13, 2007, pp. 1352-1353. doi:10.1056/NEJMc070508

[5] V. Kouri, A. Marini, R. Doroudi, S. Nambiar, M. E. Rodriguez, V. Capo, et al., "Molecular Epidemiology of Kaposi's Sarcoma Herpesvirus (KSHV) in Cuban and German Patients with Kaposi's Sarcoma (KS) and Asymptomatic Sexual Contacts," Virology, Vol. 337, No. 2, 2005, pp. 297-303. doi:10.1016/j.virol.2005.04.033

[6] V. Kouri, X. Liang, M. E. Rodriguez, V. Capo, S. Resik, J. Barrios, et al., "Molecular Epidemiology and KSHV 
K1 Subtypes in a Cuban AIDS-Kaposi's Sarcoma Population," Aids, Vol. 19, No. 9, 2005, pp. 984-987. doi:10.1097/01.aids.0000171416.07034.d6

[7] V. Kouri, P. A. Martinez, V. Capo, O. Blanco, M. E. Rodriguez, N. Jimenez, et al., "Kaposi's Sarcoma and Human Herpesvirus 8 in Cuba: Evidence of Subtype B Expansion," Virology, Vol. 432, No. 2, 2012, pp. 361-369. doi:10.1016/j.virol.2012.06.014

[8] R. Kumar, A. Abbas, A. DeLancey and E. Malone, "Diseases of the Immune System," In: R. Kumar, A. Abbas, A. DeLancey and E. Malone, Eds., Robbins and Cotran Pathologic Basis of Disease, 8 Edition, Elsevier Inc., 2010, pp. 183-257.

[9] F. Watzinger, M. Suda, S. Preuner, R. Baumgartinger, K. Ebner, L. Baskova, et al., "Real-Time Quantitative PCR Assays for Detection and Monitoring of Pathogenic Human Viruses in Immunosuppressed Pediatric Patients," Journal of Clinical Microbiology, Vol. 42, No. 11, 2004, pp. 5189-5198. doi:10.1128/JCM.42.11.5189-5198.2004

[10] V. Kouri, P. A. Martinez, O. Blanco, V. Capo, M. E. Rodriguez, C. Dovigny Mdel, et al., "Simultaneous Quantification of Human Herpesvirus 8 DNA by Real Time PCR in Different Tissues of HIV Infected Cuban Patients with Kaposi's Sarcoma," Herpesviridae, Vol. 1, No. 1, 2010, p. 3. doi:10.1186/2042-4280-1-3

[11] M. Schmitz, C. Scheungraber, J. Herrmann, K. Teller, M. Gajda, I. B. Runnebaum, et al., "Quantitative Multiplex PCR Assay for the Detection of the Seven Clinically Most Relevant High-Risk HPV Types," Journal of Clinical Virology, Vol. 44, No. 4, 2009, pp. 302-307. doi:10.1016/j.jcv.2009.01.006

[12] K. Tamura, J. Dudley, M. Nei and S. Kumar, "MEGA4: Molecular Evolutionary Genetics Analysis (MEGA) Software Version 4.0," Molecular Biology and Evolution, Vol. 24, 2007, pp. 1596-1599. doi:10.1093/molbev/msm092

[13] M. Clamp, J. Cuff, S. M. Searle and G. J. Barton, "The Jalview Java Alignment Editor," Bioinformatics, Vol. 20, 2004, pp. 426-427. doi:10.1093/bioinformatics/btg430

[14] D. Posada and K. A. Crandall, "MODELTEST: Testing the Model of DNA Substitution," Bioinformatics, Vol. 14, 1998, pp. 817-818. doi:10.1093/bioinformatics/14.9.817

[15] N. H. Dukers and G. Rezza, "Human Herpesvirus 8 Epidemiology: What We Do and Do Not Know," Aids, Vol. 17, No. 12, 2003, pp. 1717-1730. doi:10.1097/00002030-200308150-00001

[16] A. G. Marcelin, J. Motol, A. Guihot, E. Caumes, J. P. Viard, E. Dussaix, et al., "Relationship between the Quantity of Kaposi Sarcoma-Associated Herpesvirus (KSHV) in Peripheral Blood and Effusion Fluid Samples and KSHV-Associated Disease," Journal of Infectious Disease, Vol. 196, No. 8, 2007, pp. 1163-1166. doi:10.1086/521625

[17] Y. Asahi-Ozaki, Y. Sato, T. Kanno, T. Sata and H. Katano, "Quantitative Analysis of Kaposi Sarcoma-Associated Herpesvirus (KSHV) in KSHV-Associated Diseases," Journal of Infectious Disease, Vol. 193, No. 6, 2006, pp. 773-782. doi:10.1086/500560

[18] C. Casper, "Defining a Role for Antiviral Drugs in the
Treatment of Persons with HHV-8 Infection," Herpes, Vol. 13, No. 2, 2006, pp. 42-47.

[19] E. Kadyrova, V. Lacoste, R. Duprez, K. Pozharissky, V. Molochkov, M. Huerre, et al., "Molecular Epidemiology of Kaposi's Sarcoma-Associated Herpesvirus/Human Herpesvirus 8 Strains from Russian Patients with Classic, Posttransplant, and AIDS-Associated Kaposi's Sarcoma," Journal of Medical Virology, Vol. 71, No. 4, 2003, pp. 548-556. doi: $10.1002 / \mathrm{jmv} .10530$

[20] O. Cassar, M. L. Blondot, S. Mohanna, G. Jouvion, F. Bravo, V. Maco, et al., "Human Herpesvirus 8 Genotype E in Patients with Kaposi Sarcoma, Peru," Emerging Infectious Diseases, Vol. 16, No. 9, 2010, pp. 1459-1462. doi:10.3201/eid1609.100381

[21] R. J. Biggar, D. Whitby, V. Marshall, A. C. Linhares and F. Black, "Human Herpesvirus 8 in Brazilian Amerindians: A Hyper-Endemic Population with a New Subtype," Journal of Infectious Diseases, Vol. 181, No. 5, 2000, pp. 1562-1568. doi:10.1086/315456

[22] R. Alegre, J. Moscoso, J. Martinez-Laso, M. Martin-Villa, J. Suarez, A. Moreno, et al., "HLA Genes in Cubans and the Detection of Amerindian Alleles," Molecular Immunology, Vol. 44, No. 9, 2007, pp. 2426-2435. doi:10.1016/j.molimm.2006.10.017

[23] V. Kouri, P. A. Martinez, B. Acosta, M. E. Rodriguez, O. Blanco, V. Capo, et al., "First report of Kaposi's Sarcoma-Associated Herpesvirus DNA Sequences from Cuban Kaposi's Sarcoma Patients without HIV Infection," Aids, Vol. 21, No. 15, 2007, pp. 2113-2115. doi:10.1097/QAD.0b013e3282f01cc6

[24] E. Cesarman, "Gammaherpesvirus and Lymphoproliferative Disorders in Immunocompromised Patients," Cancer Letters, Vol. 305, No. 2, 2011, pp. 163-174. doi:10.1016/j.canlet.2011.03.003

[25] A. D’Antonio, M. Addesso, D. Memoli, P. Liguori, R. Cuomo, A. Boscaino, et al., "Lymph Node-Based Disease and HHV-8/KSHV Infection in HIV Seronegative Patients: Report of Three New Cases of a Heterogeneous Group of Diseases," International Journal of Hematology, Vol. 93, No. 6, 2011, pp. 795-801. doi:10.1007/s12185-011-0849-0

[26] A. Chadburn, E. Hyjek, S. Mathew, E. Cesarman, J. Said and D. M. Knowles, "KSHV-Positive Solid Lymphomas Represent an Extra-Cavitary Variant of Primary Effusion Lymphoma," The American Journal of Surgical Pathology, Vol. 28, No. 11, 2004, pp. 1401-1416. doi:10.1097/01.pas.0000138177.10829.5c

[27] E. A. Engels, S. M. Mbulaiteye, E. Othieno, M. Gomez, S. Mathew, E. Cesarman, et al., "Kaposi Sarcoma-Associated Herpesvirus in Non-Hodgkin Lymphoma and Reactive Lymphadenopathy in Uganda," Human Pathology, Vol. 38, No. 2, 2007, pp. 308-314. doi:10.1016/j.humpath.2006.08.009

[28] V. Lacoste, E. Kadyrova, I. Chistiakova, V. Gurtsevitch, J. G. Judde and A. Gessain, "Molecular Characterization of Kaposi's Sarcoma-Associated Herpesvirus/Human Herpesvirus-8 Strains from Russia," Journal of General Virology, Vol. 81, No. P5, 2000, pp. 1217-1222. 
[29] J. Zong, D. M. Ciufo, R. Viscidi, L. Alagiozoglou, S. Tyring, P. Rady, et al., "Genotypic Analysis at Multiple Loci across Kaposi's Sarcoma Herpesvirus (KSHV) DNA Molecules: Clustering Patterns, Novel Variants and Chimerism," Journal of Clinical Virology, Vol. 23, No. 3, 2002, pp. 119-148. doi:10.1016/S1386-6532(01)00205-0

[30] L. A. Dourmishev, A. L. Dourmishev, D. Palmeri, R. A. Schwartz and D. M. Lukac, "Molecular Genetics of Kaposi's Sarcoma-Associated Herpesvirus (Human Herpesvirus-8) Epidemiology and Pathogenesis," Microbiology and Molecular Biology Reviews, Vol. 67, No. 2, 2003, pp. 175-212. doi:10.1128/MMBR.67.2.175-212.2003

[31] E. Oksenhendler, D. Cazals-Hatem, T. F. Schulz, V. Barateau, L. Grollet, J. Sheldon, et al., "Transient Angiolymphoid Hyperplasia and Kaposi's Sarcoma after Primary Infection with Human Herpesvirus 8 in a Patient with Human Immunodeficiency Virus Infection," New England Journal of Medicine, Vol. 338, No. 22, 1998, pp. 1585-1590. doi:10.1056/NEJM199805283382204

[32] M. Luppi, P. Barozzi, V. Rasini, G. Riva, A. Re, G. Rossi, et al., "Severe Pancytopenia and Hemophagocytosis after
HHV-8 Primary Infection in a Renal Transplant Patient Successfully Treated with Foscarnet," Transplantation, Vol. 74, No. 1, 2002, pp. 131-132. doi:10.1097/00007890-200207150-00023

[33] O. Thaunat, M. F. Mamzer-Bruneel, F. Agbalika, F. Valensi, M. Venditto, C. Lebbe, et al., "Severe Human Herpesvirus-8 Primary Infection in a Renal Transplant Patient Successfully Treated with Anti-CD20 Monoclonal Antibody," Blood, Vol. 107, No. 7, 2006, pp. 3009-3010. doi:10.1182/blood-2005-08-3213

[34] M. Andreoni, L. Sarmati, E. Nicastri, G. El Sawaf, M. El Zalabani, I. Uccella, et al., "Primary Human Herpesvirus 8 Infection in Immunocompetent Children," Jama, Vol. 287 , No. 10,2002 , pp. $1295-300$. doi:10.1001/jama.287.10.1295

[35] F. C. Kasolo, J. Spinks, H. Bima, M. Bates and U. A. Gompels, "Diverse Genotypes of Kaposi's Sarcoma Associated Herpesvirus (KSHV) Identified in Infant Blood Infections in African Childhood-KS and HIV/AIDS Endemic Region," Journal of Medical Virology, Vol. 79, No. 10, 2007, pp. 1555-1556. doi:10.1002/jmv.20952 